\title{
A TEORIA DE GOUGH E O MODELO ASCENDENTE DE LEITURA
}

\author{
Dioni Maria dos Santos Paz \\ dioni-paz@uergs.edu.br
}

\section{RESUMO}

Este texto objetiva mostrar um modelo de leitura em nível de cognição: o modelo bottom-up de Gough $(1972,1985)$. Em linhas gerais, essa teoria defende a idéia de que o estudo do vocabulário é um importante propósito durante o processo da leitura tanto em primeira língua quanto em segunda língua, porém defendemos a tese de que o desenvolvimento do vocabulário e as habilidades gramaticais só surtirão efeitos positivos quando estudados em redes semânticas e conceituais.

\section{INTRODUÇÃO}

A psicolingüística vem sendo propagada como um ponto de articulação entre a psicologia cognitiva e a lingüística com o propósito de investigar a interação entre pensamento e linguagem. Essa área de estudos tem trazido muitas contribuições para a compreensão dos processos do pensamento e a formação de conceitos. Nessas investigações, encaixam-se os processos cognitivos realizados pelos sujeitos durante a leitura.

\section{CONSIDERAÇÕES SOBRE OS MODELOS COGNITIVOS DE LEITURA}

Segundo Samuels \& Kamil (1988, p.22),

\begin{abstract}
... sérias tentativas em construir modelos explícitos do processo de leitura - modelos que descrevem o processo inteiro desde o momento em que o olho encontra a página até as experiências do leitor com o "click da compreensão" - têm uma história de pouco mais de trinta anos....É talvez mais certo especular que até a metade dos anos 50 e 60 não havia simplesmente uma tradição forte para tentar conceituar o conhecimento e a teoria sobre o processo de leitura na forma de modelos em leitura explícita. (Tradução minha)
\end{abstract}

Teoricamente existem três modelos básicos de leitura em nível de cognição: o modelo ascendente (bottom-up) defendido por Gough $(1972,1985)$, que privilegia (as partes) as palavras e expressões do texto; o modelo descendente (top-down) defendido por Goodman $(1976,1985,1988)$, que processa (globalmente) a leitura por hipotetização, considerando o conhecimento prévio do leitor; e o modelo interativo defendido por Rumelhart $(1977,1985)$, que processa os dois subprocessos bottom-up e top-down simultaneamente ou alternadamente. 
Aebersold \& Field (1997, p.18), trabalhando numa perspectiva pedagógica, apresentam os três modelos nos seguintes termos:

1. A teoria bottom-up argumenta que o leitor constrói o texto das pequenas uni-
dades (letras para palavras para frases para sentenças, etc.)...Decodificação é o
termo para esse processo. 2. A teoria top-down argumenta que os leitores tra-
zem seu próprio conhecimento, suas experiências e suas dúvidas para o texto...
e continuam lendo-o até que as hipóteses ditas anteriormente sejam confirma-
das...3. A teoria interativa...argumenta que os processos top-down e bottom-up
ocorrem alternados ou ao mesmo tempo. (Tradução minha)

Nessa visão, o primeiro tipo de leitor é aquele que enfatiza o processo ascendente, construindo o significado principalmente com base nos dados do texto, fazendo pouca leitura ou quase nenhuma nas entrelinhas do texto, detendo-se vagarosamente nas palavras. Esse procedimento (Gough, op.cit) valoriza o vocabulário do texto, dando atenção às partes menores do texto.

O segundo tipo de leitor privilegia a abordagem descendente (Goodman, op.cit) em seus modelos de aprendizagem, ou seja, privilegia o leitor que apreende rapidamente as idéias gerais e essenciais do texto, é fluente, mas deve ter cuidado para não fazer excessos de adivinhações do significado geral. Conseqüentemente, este tipo de leitor é o que faz mais uso de seu conhecimento prévio do que da informação propriamente dita do texto. Nesse processo descendente, o leitor estimula os chamados pacotes de esquemas, isto é, conhecimentos já estruturados, acompanhados de instruções para determinado uso. Esses pacotes de esquemas ligam-se a outros esquemas ou subesquemas e acionam uma rede de interrelações que são ativadas no ato da leitura, produzindo significações e situações novas, da mesma forma que um indivíduo é capaz de entender e produzir sentenças nunca antes ouvidas.

O terceiro tipo de leitor é aquele que processa os dois modelos paralelamente (Rumelhart, op.cit), conforme as exigências do texto e da situação do contexto. Podemos registrar que se trata de um leitor maduro e competente, com alto grau de proficiência em leitura.

Neste artigo, apresentaremos o modelo ascendente, ou seja, o modelo bottom-up de Gough.

\section{O MODELO ASCENDENTE (BOTTOM-UP) DE GOUGH}

Segundo Samuels \& Kamil (1988), com a publicação do modelo de leitura de Gough (1972), o impacto da abordagem de processamento da informação ao estudar os processos mentais é sentida dentro do campo da leitura.

Por causa das hipóteses do autor de que todas as letras no campo visual devam ser consideradas individualmente pelo leitor, anteriormente à indicação do significado para qualquer série de letras, esse modelo tem gerado muitas controvérsias 
sobre os processos básicos, como o modelo de Goodman $(1976,1985)$ tem sobre a prática instrumental. Mas o mais importante é saber o que é feito com as letras.

\begin{abstract}
Claramente, as letras não são a matéria da qual as sentenças são feitas. Elas devem estar associadas com significados; elas devem ser mapeadas nas entradas no léxico mental. A especificação do mecanismo pelo qual isto é realizado é, como eu o vejo, o problema fundamental da leitura (Gough, 1985, p.664). (Tradução minha)
\end{abstract}

Para o autor, a leitura começa com uma fixação dos olhos. Os olhos do leitor focalizam um ponto levemente recuado do começo da linha, e eles permanecem naquela fixação por alguns segundos. Então eles varrerão graus do ângulo visual em um movimento rápido dos olhos, e uma nova fixação começará. Excetuando as regressões, e ignorando as varreduras de retorno esta seqüência será repetida, contanto que a leitura continue. Quando a fixação inicial é alcançada, um modelo visual é refletido na retina. Isso estabelece em movimento uma seqüência intrincada de atividades no sistema visual, culminado na formação do ícone.

Segundo algumas pesquisas, podemos destacar duas formas de ajudar os leitores de língua materna ou de uma segunda língua a melhorar o processo bottom-up: as habilidades gramaticais e o desenvolvimento de vocabulário.

\title{
4. AS HABILIDADES GRAMATICAIS NO MODELO BOTTOM-UP
}

Vários estudos têm mostrado o importante papel desempenhado pelo conhecimento gramatical na leitura nativa e não-nativa. Carrell (1988) mostra o estudo de Chapman (1979) realizado com crianças nativas falantes de inglês (na GrãBretanha). Essa pesquisa descobriu um relacionamento entre a habilidade de leitura e a habilidade de completar relações anafóricas em um teste cloze, e ele concluiu que o domínio de tais características textuais, incluindo laços coesivos, como sabemos, fartamente estudados por Halliday \& Hasan (1976), é um fator central na leitura fluente e na compreensão em leitura. Carrell (op.cit.) também registra o estudo de Cohen e pesquisadores (1979).

Eles descobriram que os leitores estrangeiros de textos em inglês nas ciências e economia freqüentemente não assimilavam as palavras conjuntivas em seus textos especializados. Diante disso, esses pesquisadores argumentaram que os leitores não-nativos lêem mais localmente do que os falantes nativos e, por que eles não observam laços conjuntivos, eles têm problemas em sintetizar a informação através das sentenças e parágrafos.

Carrell (1988) também registra que Cowan (1976) e Mackay (1979) têm similarmente argumentado que o reconhecimento das conjunções, e outros instrumentos lingüísticos entre sentenças, é crucial para as habilidades na reunião de informação para leitores de uma segunda língua. Portanto, intensificar as habilidades de decodificação bottom-up para leitores em uma segunda língua deve incluir a ins- 
trução em sala de aula sobre os instrumentos coesivos (substituição, elipse, conjunção, coesão lexical) e sua função entre as sentenças e parágrafos. Tal instrução pode tornar os estudantes cientes de como as idéias em um texto são unificadas por esses elementos coesivos.

Citando Connor (1984), Carrell (op.cit.) mostra que outro estudo sobre coesão e coerência em composições de alunos avançados descobriu que embora os escritores avançados usassem quase a mesma proporção de instrumentos coesivos como os escritores nativos, faltava-lhes a variedade dos escritores nativos.

Isso é especialmente verdade na categoria da coesão lexical, em que escritores tendem a usar demais a repetição e a não usar sinônimos e colocações. O autor atribuiu isso a deficiências gerais no vocabulário desses alunos e comentou que isso parece estar relacionado a resultados similares com bons e ruins escritores de inglês nativo. Para Carrell (op. cit.), esta constatação é o que impulsiona a instrução das habilidades de decodificação bottom-up de leitores em segunda língua: o desenvolvimento de vocabulário.

\section{DESENVOLVIMENTO DE VOCABULÁRIO COMO HABILIDADE BOTTOM-UP}

Segundo Carrell (1988, p.242),

o desenvolvimento de vocabulário e o reconhecimento da palavra têm sido reconhecido por longo tempo como crucial para as habilidades de decodificação bottom-up de sucesso. Contudo, a teoria dos esquemas tem emitido nova luz sobre a natureza complexa do inter-relacionamento do conhecimento dos esquemas, contexto e vocabulário. (Tradução minha)

Para a autora, diferentemente das visões convencionais de vocabulário, o pensamento atual converge sobre a noção de que uma dada palavra não tem um significado fixo, mas sim tem uma variedade de significados ao redor de um núcleo prototípico, e que esses significados interagem com o contexto e o conhecimento prévio.

Nessa ótica, podemos afirmar que se os leitores não têm as experiências práticas associadas às palavras em diferentes contextos, a compreensão dos itens lexicais e as sentenças por inteiro serão afetadas. Portanto, o conhecimento dos significados individuais das palavras está fortemente associado ao conhecimento conceitual, isto é, aprender vocabulário é também aprender o conhecimento conceitual associado à palavra.

Por um lado, uma parte importante de se ensinar conhecimento prévio é ensinar o vocabulário relacionado a ele, e de modo inverso, ensinar vocabulário pode significar ensinar novos conceitos, novos conhecimentos. O conhecimento de vocabulário vincula conhecimento dos esquemas, nos quais um conceito participa do co- 
nhecimento das redes, das quais aquela palavra participa, bem como quaisquer palavras associadas e os conceitos.

Carrell (op. cit.) também alerta que os professores devem estar conscientes das diferenças interculturais no vocabulário e como o significado pode ser representado diferentemente nas palavras de várias línguas. Por esse motivo, as correlações entre o conhecimento dos significados das palavras e a habilidade de compreender passagens contendo aquelas palavras são mais fáceis e bem estabelecidas em estudos de leitura em primeira língua. Tal evidência, certamente, falha ao estabelecer o conhecimento dos significados das palavras como uma causa da compreensão.

Por sua vez, estudos sobre a compreensão da leitura em primeira e segunda línguas, que empregam a instrução em pré-leitura nos significados das palavras, têm sido igualmente positivos e negativos ao realizar um efeito significante. Enquanto quaisquer conclusões traçadas de uma análise de apenas poucos estudos devam ser vistas como experimental, várias características parecem distinguir programas de ensino efetivos e não-efetivos.

Particularmente, acredito que pré-ensinar vocabulário, a fim de aumentar a compreensão do texto, terá sucesso se as palavras a serem ensinadas forem palavras-chave em passagens-alvo, e forem ensinadas em conjuntos semanticamente e topicamente relacionados, de modo que os significados das palavras e o conhecimento prévio melhorem simultaneamente (Paz, 2006). É relevante que as palavras sejam apreendidas inteiramente, isto é, que ambas as informações de definição e contextual estejam envolvidas, para que haja um engajamento mais profundo dos significados. Portanto, ensinar os significados das palavras sem determinar que elas são chave para as passagens-alvo, como pistas para a formação de hipóteses relativas ao assunto do texto, poderá levar ao fracasso.

Dentro dessa visão, Tomitch (1995) aponta, em seu estudo, resultados positivos no ensino de vocabulário e leitura. A autora registra que desenvolver vocabulário só terá êxito se for pensado em termos conceituais, como uma rede interligada de conceitos que representem idéias de parentescos semânticos, que levem o aluno a acionar o esquema adequado às idéias principais, para chegar à compreensão do texto.

Nessa mesma perspectiva, uma pesquisa específica em leitura em segunda língua, realizada por Hudson (1982), mencionado por Carrell (1988), tem mostrado que, simplesmente, apresentar uma lista de itens de vocabulário novo ou não familiar para ser encontrado em um texto, até mesmo com definições apropriadas a seu uso naquele texto, não garante a aprendizagem da palavra ou conceito da palavra, ou uma compreensão de leitura melhorada sobre a passagem do texto, caso não haja uma relação entre os campos semânticos e conceituais.

Segundo Carrell (op. cit. p.244), 


\begin{abstract}
...para ser efetivo, um programa de desenvolvimento extensivo e a longo prazo de vocabulário, acompanhando um esquema paralelo ou um programa de desenvolvimento de conhecimento prévio, é provavelmente exigido. Ao invés de pré-ensinar vocabulário em passagens de leitura únicas, os professores devem provavelmente estar pré-ensinando vocabulário e conhecimento prévio simultaneamente em conjuntos de passagens a serem lidas em algum tempo posteriormente. (Tradução minha)
\end{abstract}

Com efeito, esta recomendação resultaria em um tipo de currículo espiral, segundo Bruner (1960), citado por Carrell (1988), no qual o conhecimento e o vocabulário ensinado sobre um tópico admitiria o conhecimento e o vocabulário aprendido previamente sobre aquele tópico e forneceria uma nova base de conhecimento e vocabulário sobre o qual, mais tarde, o conhecimento e o vocabulário sobre aquele tópico poderia ser construído. Com essas colocações, podemos registrar que cada currículo em leitura, principalmente em segunda língua, deveria ter um programa geral de desenvolvimento de conhecimento prévio/conceito paralelo ao desenvolvimento de vocabulário.

\title{
6. CONSIDERAÇÕES FINAIS
}

Em termos cognitivos, o modelo bottom-up, ou processamento ascendente, faz uma leitura indutiva, linear das informações, construindo o significado através da análise e síntese do significado das partes. Conseqüentemente, desenvolver o vocabulário em uma primeira língua ou segunda língua não é simplesmente ensinar novos rótulos para conceitos familiares. Seu objetivo também deve ser o de envolver o ensino de novos conceitos, visto que, ao processar os esquemas semânticos relacionados aos conceituais, o leitor está evoluindo em ganhos de compreensão total do texto.

\section{BIBLIOGRAFIA}

AEBERSOLD, J. A.; FIELD, M. L. From Reader to Reading Teacher: issues and strategies for second language classroom. Cambridge: Cambridge University Press, 1997.

CARRELL, P.L. Interactive text processing: implications for ESL/second language reading classrooms. In: CARRELL, P.L; DEVINE, J.; ESKEY, D.E. (eds.). Interactive approaches to second language reading. Cambridge: Cambridge University Press, 1988, p.239-257.

GOODMAN. Kenneth. Learning to read is natural. In: Conferência sobre teoria e prática da instrução do começo da leitura. University of Pittsburg,1976.

. Unity in reading. In: SINGER H. \& RUDDELL, R. B. Theoretical model and processes of reading. Newark Delaware: Internacional Reading Association,1985, p.813-840. 
. The reading process. In: CARRELL, P. L.;DEVINE, J.; ESKEY, D.E.(eds.). Interactive approaches to second language reading. Cambridge: Cambridge University Press, 1988, p.11-21.

GOUGH, P. B. One second of reading. In: KAVANAGH, J.F. \& MATTINGLY, I.G.(orgs). Language by ear and by eye. Cambridge: MIT Press,1972, p.353-378). . One second of reading. In: SINGER H. \& RUDDELL, R. B. Theoretical model and processes of reading. Newark Delaware: Internacional Reading Association, 1985, p.661-686.

HALLIDAY, M. A. K; HASAN, R. Cohesion in English. London: Longman, 1976.

PAZ, D. M. S. Formação de conceitos de ensino de leitura em português como segunda língua. Tese (Doutorado em Letras - Estudos Lingüísticos). Universidade Federal de Santa Maria, RGS, 2006.

RUMELHART, D. E. Toward na interactive model of reading. In: DORNIC, S. Attention and performance VI. Hillsdale, N.J.: Erlbaum, 1977, p.575-603.

RUMELHART, D. E.Toward an interative model of reading. In: SINGER, H; RUDDELL, R. Theoretical models and process of reading. 3ed. Newark, International Reading Association, 1985, p.722-751.

SAMUELS, J.; KAMIL, M. Models of the reading process. In: CARRELL, P. L.;DEVINE, J.; ESKEY, D.E. (eds). Interactive approaches to second language reading. Cambridge: Cambridge University Press, 1988, p.22-36.

TOMITCH, L.M.B. Reading: text organization perception and working memory capacity. Unpublished doctoral dissertation. Tese (Doutorado em Lingüística Aplicada ao Inglês). Universidade Federal de Santa Catarina, Florianópolis, 1995. 